\title{
Variation and Inheritance of Isozymes in Safflower
}

\author{
J. Carapetian ${ }^{1}$ \\ Department of Biology, University of Urmia, Urmia 57135, Iran
}

\author{
A. Estilai ${ }^{2}$ and A. Hashemi ${ }^{3}$ \\ Department of Botany and Plant Sciences, University of California, Riverside, CA 92521
}

Additional index words. starch gel electrophoresis, isozyme markers, menadione reductase, phosphoglucoisomerase, triosephosphate isomerase, breeding, Carthamus tinctorius, oilseed

\begin{abstract}
To detect isozyme variation, leaf extracts of more than 460 plants from 20 safflower (Carthamus tinctorius L.) entries with diverse geographic origins were analyzed. Entries included seven Iranian spring-type selections, eight Iranian late rosette winter-type selections, four U.S. cultivars, and one Indian introduction. Starch gel electrophoresis produced distinct and repeatable banding patterns for nine of the 15 enzymes assayed. Five of these enzymes, aldolase (ALD, EC 4.1.2.13), isocitrate dehydrogenase (IDH, EC 2.7.5.1), malate dehydrogenase (MDH, EC 1.1.1.37), malic enzyme (ME, EC 1.1.1.40), and phosphoglucomutase (PGM, EC 2.7.5.1), were monomorphic. Menadione reductase (MR, EC 1.6.99.2), 6phosphogluconate dehydrogenase (6-PGDH, EC 1.1.1.44), phosphoglucoisomerase (PGI, EC 5.3.1.9), and triosephosphate isomerase (TPI, EC 5.3.1.1) were polymorphic. 6-PGDH revealed an invariable cathodal and a variable anodal zone of activity. Crosses were made between appropriate parents and $\mathrm{F}_{1}, \mathrm{BC}_{1}$, and $\mathrm{F}_{2}$ progenies were generated for segregation analyses. Two multibanded phenotypes that bred true were observed for MR. Crosses between these types produced 7banded $F_{1}$ plants. $F_{2}$ progenies segregated in parental and hybrid phenotypes in the expected 1:2:1 ratio. Both PGI and TPI showed one monomorphic and one polymorphic zone of activity. Segregation data indicated that Pgi-2 and Tpi-1 are monogenic and controlled by two codominant $F$ and $S$ alleles. The observation of the parental bands plus an intermediate band with a higher intensity in hybrid plants suggested that PGI and TPI act as dimeric enzymes in safflower. Isozyme genetic markers described in this study are useful tools for identification of hybrid individuals in this predominantly inbreeding species.
\end{abstract}

Safflower (Carthamus tinctorius L.) is an annual oilseed crop of the Compositae family and is grown commercially in Australia, Ethiopia, India, Mexico, the United States, and several other countries. Safflower was first domesticated for its flowers. Carthamin, a red dye extracted from the flowers, was used primarily to color cloths. In China, dried red and orange flowers of safflower are used for medicinal purposes. The extracted yellow and red pigments are also used for coloring foods and beverages (Knowles, 1989). The nutritional value of safflower oil is related to its high level of polyunsaturation. The oil contains about $75 \%$ linoleic acid (18:2). This fatty acid is one of the essential fatty acids for human nutrition. It has been reported that the use of safflower oil reduces the risk of coronary heart disease (Vles and Gottenbos, 1989).

Cultivated safflower is predominantly self-pollinated with $<10 \%$ outcrossing. However, higher levels of cross-pollination have been reported for some genotypes (Claassen, 1950). Approximately 20 qualitative characters have been analyzed in safflower (Knowles, 1982). The majority of the traits are under simple genetic control, except branching habit, flower color, closed floret, and male-female sterility, all of which have multigenic inheritance. Most of the traits must be observed in later stages of plant development. If tightly linked to the traits of interest, isozyme gene markers are advantageous over conventional morphological gene markers because they allow seedling screening and save considerable greenhouse and field space for the breeder. The codominant nature of allelic expression, absence of epistatic or environmental effects, and expression in a variety of plant tissues have contrib-

Received for publication 2 Feb. 1993. Accepted for publication 17 Nov. 1993. The cost of publishing this paper was defrayed in part by the payment of page charges. Under postal regulations, this paper therefore must be hereby marked advertisement solely to indicate this fact.

${ }^{1}$ Associate professor of genetics and plant breeding.

${ }^{2}$ Research agronomist.

${ }^{3}$ Postgraduate geneticist. uted to the widespread use of isozyme markers. Isozyme polymorphism has been successfully used to demonstrate genetic variation in populations, to estimate the rate of outcrossing, and to identify cultivars, species, and hybrids (Adams, 1983; Byrne and Littleton, 1988; Estilai et al., 1990; Gaur and Slinkard, 1990; Moore and Collins, 1983; Rick, 1983).

Studies of isozyme variation are rare in safflower. The only published work to date (Bassiri, 1977) reports the use of acid phosphatase and peroxidase enzymes for identification of 14 safflower cultivars and seven ecotypes of wild safflower (Carthamus oxyacantha Bieb.). In this report, we evaluate nine enzyme systems for variability in a wide array of safflower materials and report the inheritance of menadione reductase, phosphoglucoisomerase, and triosephosphate isomerase.

\section{Materials and Methods}

For evaluation of isozyme variability, 20 safflower entries of different geographic origins were used. These included seven Iranian spring-type selections, eight Iranian late rosette wintertype selections, four U.S. cultivars, and one Indian introduction (Table 1). The U.S. cultivars have their origins from different parts of the world. For instance, the variety US-10 was developed from 'N-10', a selection from a Sudanese introduction (Thomas, 1964). Seed of 'US-10' and '57-147' selection was obtained from the Univ. of California, Davis. Seed of the remaining 18 germplasm lines was received from the Iranian Oilseed Research and Development Company, Tehran. All entries were initially grown in 5-m rows during the 1991 season in experimental field plots at the Univ. of Urmia, Iran, and their phenotypic characteristics were recorded (Table 1). To detect variation in predominantly self-pollinated safflower entries, we examined an average of 23 plants individually per each entry.

For inheritance analyses, $\mathrm{F}_{1}, \mathrm{BC}_{1}$, and $\mathrm{F}_{2}$ progenies were generated by crossing appropriate homozygous parents and selfing the 
Table 1. Characteristics of 20 safflower cultivars and selections used for isozyme studies.

\begin{tabular}{|c|c|c|c|c|c|}
\hline Entry $^{z}$ & Source & Flower color ${ }^{\mathrm{y}}$ & Spininess $^{\mathrm{x}}$ & $\begin{array}{l}\text { Plant } \\
\text { ht } \\
(\mathrm{cm})\end{array}$ & $\begin{array}{c}\text { Days to } \\
50 \% \\
\text { bloom }\end{array}$ \\
\hline V49/236 & Varamin, Iran & Lt Or, Or & Spls & 90 & 70 \\
\hline V51/211 & Varamin, Iran & Or, R & Spls & 95 & 72 \\
\hline V51/241 & Varamin, Iran & Or & $\mathrm{Sp}$ & 100 & 70 \\
\hline D51/137 & Darab, Iran & Or & Spls & 115 & 74 \\
\hline D51/192 & Darab, Iran & Or, R & Spls & 105 & 74 \\
\hline E25 & Esfahan, Iran & Lt Or & Spls & 100 & 82 \\
\hline A2811 & Arak, Iran & Y, Or, R & $\mathrm{Sp}$ & 95 & 70 \\
\hline Frio 3176 & United States & Or & $\mathrm{Sp}$ & 90 & 68 \\
\hline Nebraska 10 & United States & $\mathrm{Y}$ & $\mathrm{Sp}$ & 85 & 68 \\
\hline US-10 & United States & $\mathrm{Y}$ & $\mathrm{Sp}$ & 65 & 70 \\
\hline Ute 3175 & United States & Or & $\mathrm{Sp}$ & 85 & 70 \\
\hline $57-147$ & Bihar, India & $\mathrm{R}$ & Spls & 50 & 77 \\
\hline LR 55/65 & Urmia, Iran & Or & $\mathrm{Sp}$ & 140 & 125 \\
\hline LR 55/290 & Urmia, Iran & Or, R & $\mathrm{Sp}$ & 110 & 125 \\
\hline LRV 55/51 & Urmia, Iran & Or & $\mathrm{Sp}$ & 150 & 125 \\
\hline LRV 55/67 & Urmia, Iran & Or & $\mathrm{Sp}$ & 110 & 125 \\
\hline LRV 55/277 & Urmia, Iran & Or & $\mathrm{Sp}$ & 130 & 113 \\
\hline LRV 55/292 & Urmia, Iran & Y, Or, R & $\mathrm{Sp}$ & 125 & 117 \\
\hline LRV 295 & Urmia, Iran & Or & Spls & 150 & 113 \\
\hline LRV 697 & Urmia, Iran & Or & $\mathrm{Sp}$ & 100 & 125 \\
\hline
\end{tabular}

${ }^{\mathrm{z}}$ All entries are spring-type safflower except for those starting with LR, which are Late Rosette winter-type selections.

${ }^{\mathrm{y}} \mathrm{Lt} \mathrm{Or}=$ light orange; $\mathrm{Or}=$ orange; $\mathrm{R}=$ red; $\mathrm{Y}=$ yellow .

${ }^{\mathrm{x}} \mathrm{Spls}=$ spineless; $\mathrm{Sp}=$ spiny.

$\mathrm{F}_{1}$ plants (Table 2). Emasculation and pollination techniques have been previously reported (Knowles, 1980). Seedlings were grown in a greenhouse at the Univ. of California, Riverside, and leaf samples were obtained 2 to 3 weeks after planting for isozyme analyses.

One actively growing leaf was sampled from each seedling in the morning. Leaf samples were placed in a block of a 25-well plexiglass sample grinder and kept cool on crushed ice. Two to three drops of extraction buffer were added to each sample, which was then thoroughly macerated in a well with the coarse end of a glass rod attached to a small electric drill. The extraction buffer consisted of $15 \mathrm{mg}$ DL-dithiothreitol (DTT), $1.5 \mathrm{~g}$ polyvinylpyrrolidone (PVP-40), and two drops of 2-mercaptoethanol in $10 \mathrm{ml} 0.1 \mathrm{M}$ tris $\mathrm{HCl}(\mathrm{pH} 8.0)$.

The enzymes assayed were acid phosphatase (ACP, EC 3.1.3.2), alcohol dehydrogenase (ADH, EC 1.1.1.1), aldolase (ALD, EC 4.1.2.13), formic acid dehydrogenase (FDH, EC 1.2.1.2), glucose6-phosphate dehydrogenase (G-6-PD, EC 1.1.1.49), glutamate dehydrogenase (GDH, EC 1.4.1.2), isocitrate dehydrogenase(IDH, EC 1.1.1.42), malate dehydrogenase (MDH, EC 1.1.1.37), malic enzyme (ME, EC 1.1.1.40), menadione reductase (MR, EC 1.6.99.2), phosphoglucomutase (PGM, EC 5.4.2.2), 6phosphogluconate dehydrogenase (6-PGDH, EC 1.1.1.44), phosphoglucoisomerase (PGI, EC 5.3.1.9), shikimate dehydrogenase (SKDH, EC 1.1.1.25), and triosephosphate isomerase (TPI, EC 5.3.1.1).

Three starch gel systems, histidine citrate (HC), morpholine citrate (MC), and lithium borate (LB), were used to assay the above enzyme systems. The HC system was not as satisfactory as the other two systems. In the MC continuous system, the gel consisted of $9.6 \%$ starch and $0.0016 \mathrm{~m}$ citric acid, and the electrode buffer contained $0.04 \mathrm{M}$ citric acid. Both buffers were titrated to $\mathrm{pH} 7.0$ by the addition of $N$-(3-amino-propyl)-morpholine (O'Malley et al., 1980). Aldolase, MDH, ME, PGM, 6-PGDH, and PGI were studied with the MC system. In the LB discontinuous system, the gel had a starch concentration of $10.9 \%$, and contained $0.051 \mathrm{M}$ tris,

Table 2. Monogenic segregation of enzyme loci in safflower crosses.

\begin{tabular}{|c|c|c|c|c|c|c|c|}
\hline Enzyme & Crosses and genotypes & $\begin{array}{c}\text { No. of } \\
\text { families }\end{array}$ & No. of progenies and genotypes & ratio & $\chi^{2}$ & $\mathrm{P}$ & $\begin{array}{c}\chi^{2} \\
\text { (heterogeneity) }\end{array}$ \\
\hline \multirow[t]{2}{*}{ MR } & D51/192 (type 1$) \times V 51 / 211(\text { type } 2)^{*}$ & 1 & 10 (hybrid) & --- & --- & --- & --- \\
\hline & $\mathrm{F}_{1}($ hybrid $) \times \mathrm{F}_{1}($ hybrid $)$ & 3 & 29 (type 1) : 54 (hybrid) : 22 (type 2) & $1: 2: 1$ & 1.02 & 0.61 & $1.38(4 \mathrm{df})$ \\
\hline \multirow[t]{3}{*}{ PGI-2 } & Nebraska $10(\mathrm{SS}) \times$ D51/192 (FF) & 1 & $7(\mathrm{FS})$ & --- & --- & --- & --- \\
\hline & $\mathrm{F}_{1}(\mathrm{FS}) \times \mathrm{F}_{1}(\mathrm{FS})$ & 4 & $47(\mathrm{FF}): 91(\mathrm{FS}): 51(\mathrm{SS})$ & $1: 2: 1$ & 0.43 & 0.81 & $9.97(6 \mathrm{df})$ \\
\hline & $\mathrm{F}_{1}(\mathrm{FS}) \times \mathrm{D} 51 / 192(\mathrm{FF})$ & 1 & $11(\mathrm{FF}): 13(\mathrm{FS})$ & $1: 1$ & 0.17 & 0.69 & --- \\
\hline \multirow[t]{3}{*}{ TPI-1 } & US-10 (FF) $\times 57-147(\mathrm{SS})$ & 1 & $11(\mathrm{FS})$ & --- & --- & --- & --- \\
\hline & $\mathrm{F}_{1}(\mathrm{FS}) \times \mathrm{F}_{1}(\mathrm{FS})$ & 3 & $32(\mathrm{FF}): 54(\mathrm{FS}): 27(\mathrm{SS})$ & $1: 2: 1$ & 0.66 & 0.72 & $5.95(4 \mathrm{df})$ \\
\hline & $\mathrm{F}_{1}(\mathrm{FS}) \times \mathrm{US}-10(\mathrm{FF})$ & 1 & $13(\mathrm{FF}): 21(\mathrm{FS})$ & $1: 1$ & 1.88 & 0.18 & --- \\
\hline
\end{tabular}

*Type 1 and 2 refer to Figure 1, MR, lane 1 and 2 electromorphs, respectively. 
Migration Distance $(\mathrm{mm})$

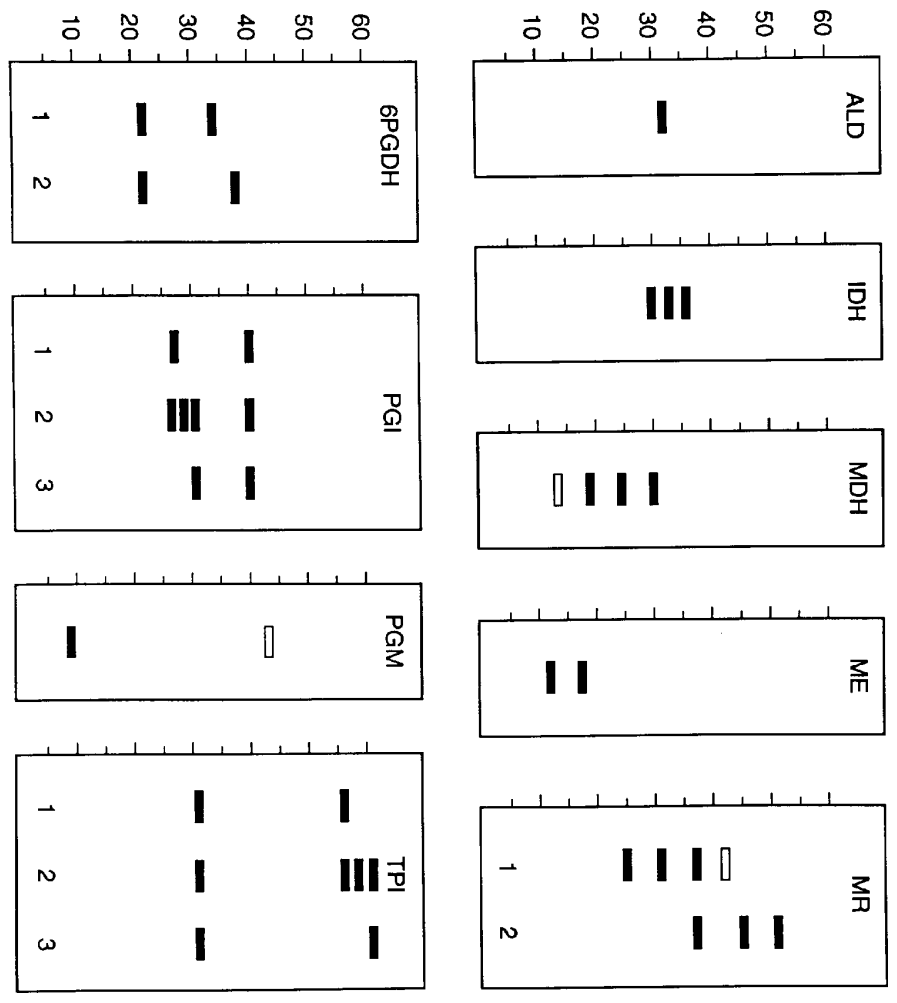

Fig. 1. Schematic illustrations of banding patterns for nine enzyme systems in safflower. Open rectangles represent weakly staining bands.

$0.0076 \mathrm{~m}$ citric acid, $0.0028 \mathrm{M} \mathrm{LiOH}$, and $0.019 \mathrm{~m}$ boric acid. The electrode buffer in this system consisted of $0.023 \mathrm{~m} \mathrm{LiOH}$ and 0.154 м boric acid (Heywood, 1980). Isocitrate dehydrogenase, MR, and TPI were assayed with the LB system.

Sample extracts were absorbed on $1 \times 10$-mm filter paper wicks. The wicks were lightly blotted and were run immediately or were stored overnight below $0 \mathrm{C}$ in a compartmentalized plate. Twenty to 30 wicks were inserted into a transverse cut $3 \mathrm{~cm}$ from the cathodal end of the gel. Electrophoresis was conducted in a cold chamber at $4 \mathrm{C}$, with a plastic sheet and a tray of ice placed on each gel. Duration, current, and voltage for electrophoresis varied with the gel system. The MC gels were run at $150 \mathrm{~V}$ and $30 \mathrm{~mA}$ for $5 \mathrm{~h}$, and the LB gels were run at $200 \mathrm{~V}$ and $75 \mathrm{~mA}$ for $6 \mathrm{~h}$. After the completion of electrophoresis, each gel was sliced into four 1.5mm slabs, all of which were stained.

The procedures of Garvin (1987) were used for staining IDH, ME, 6-PGDH, PGI, and PGM. For staining MDH and TPI, the procedures of Soltis et al. (1983), as modified by Estilai et al. (1990), were used. The methods described by Conkle et al. (1982) were employed for staining ALD and MR. All gels were stained in the dark until bands appeared. Gels assayed for MR were stained at room temperature. The gels stained for all other enzymes were incubated at $27 \mathrm{C}$. Stained gels were fixed in $50 \%$ ethanol.

\section{Results and Discussion}

Nine of the 15 enzyme systems, ALD, IDH, MDH, ME, MR, PGM, 6-PGDH, PGI, and TPI, produced distinct and repeatable banding patterns. In spite of diverse geographic origins, different growth habits, and varied morphological features (Table 1), the 20 safflower entries of this survey were uniform for ALD, IDH, $\mathrm{MDH}, \mathrm{ME}$, and PGM (Fig. 1). The invariant nature of these enzymes in highly homozygous safflower plants indicates the lack of recognizable allelic diversity, and hence precludes inheritance studies for these enzymes. An inherent weakness of electrophoretic methodology is that it does not distinguish all genetic variability at a structural gene locus. One reason for this shortcoming is that only about $30 \%$ of amino acid substitutions on the exterior of an enzyme molecule result in a charge shift, recognizable as an electrophoretic variant (May, 1992).

Polymorphisms were observed for MR, 6-PGDH, PGI, and TPI isozymes. 6-PGDH showed two zones of activity (Fig. 1, 6PGDH). The slower cathodal zone was invariable in all samples. The anodal zone was expressed in two electromorphs. The fast electromorph was found only in two of the late rosette selections

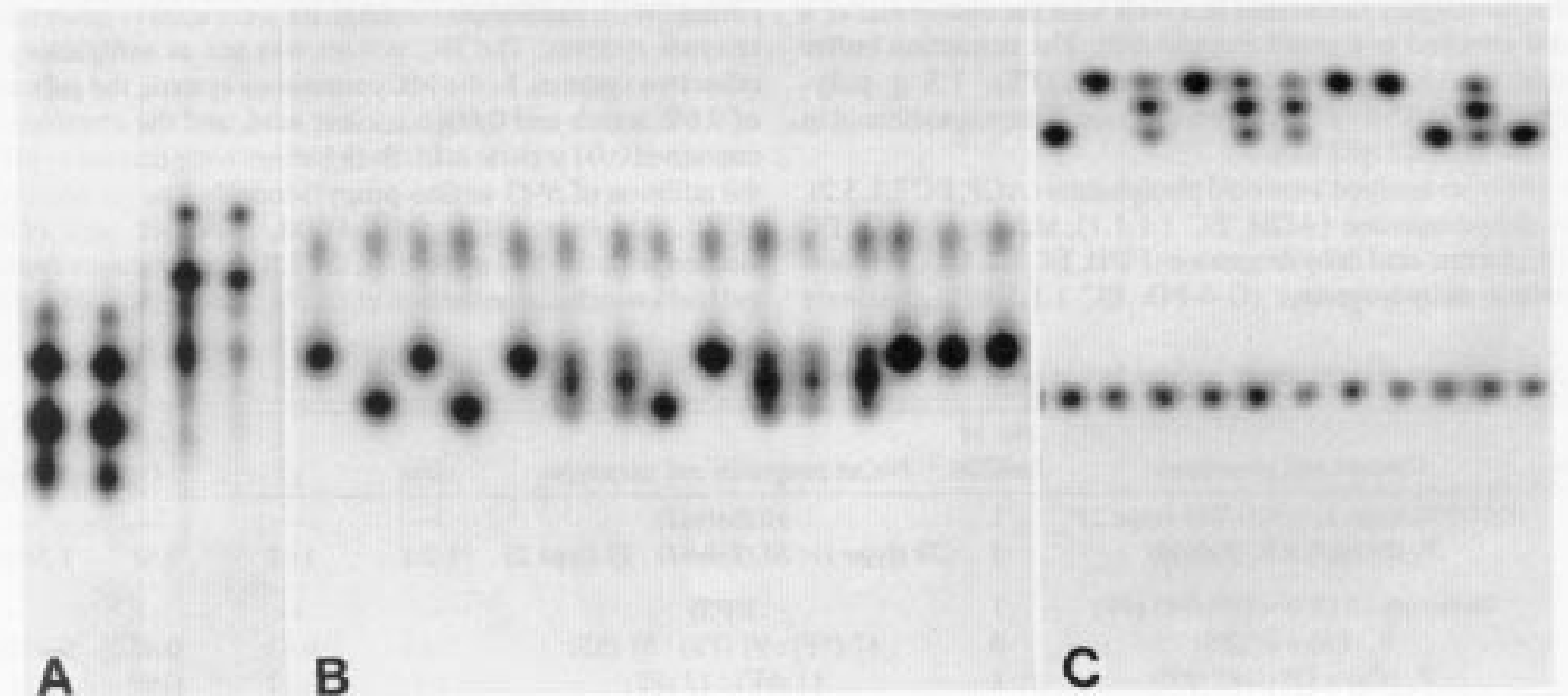

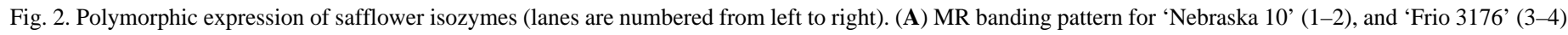

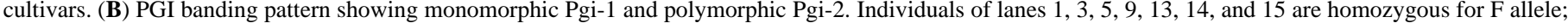

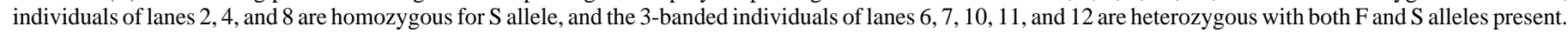

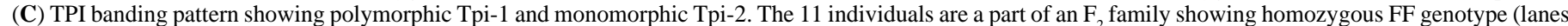
2, 4, 7, and 8); homozygous SS genotype (lanes 1, 9, and 11); and heterozygous FS genotype (lanes 3, 5, 6, and 10). 
Table 3. Phenotypic characterization of four isozymes in 20 safflower entries.

\begin{tabular}{|c|c|c|c|c|c|c|c|c|c|c|c|c|}
\hline \multirow[b]{3}{*}{ Entry } & \multicolumn{12}{|c|}{ Enzymes } \\
\hline & \multicolumn{3}{|c|}{ MR } & \multicolumn{3}{|c|}{ 6-PGDH-1 } & \multicolumn{3}{|c|}{ PGI-2 } & \multicolumn{3}{|c|}{ TPI-1 } \\
\hline & Type 1 & Hybrid & Type 2 & FF & FS & SS & $\mathrm{FF}$ & FS & SS & $\mathrm{FF}$ & FS & SS \\
\hline V49/236 & + & & & & & + & + & & & + & & \\
\hline V51/211 & & & + & & & + & + & & & + & & \\
\hline V51/241 & + & & & & & + & + & & & + & & \\
\hline D51/137 & + & & & & & + & + & & & + & & \\
\hline D51/192 & + & & & & & + & + & & & + & & \\
\hline E25 & + & & & & & + & + & & & + & & \\
\hline A 2811 & + & & & & & + & + & + & + & + & & \\
\hline Frio 3176 & & & + & & & + & + & + & + & + & & \\
\hline Nebraska 10 & + & & & & & + & & & + & + & & \\
\hline US-10 & + & & & & & + & & & + & + & & \\
\hline Ute 3175 & + & & & & & + & + & & & & & + \\
\hline $57-147$ & + & & & & & + & & & + & & & + \\
\hline LR 55/65 & + & & & & & + & + & & & & & + \\
\hline LR 55/290 & + & & & & & + & + & & & & & + \\
\hline LRV 55/51 & + & & & & & + & + & + & + & & & + \\
\hline LRV 55/67 & + & & & + & & & + & & & & & + \\
\hline LRV 55/277 & + & & & & & + & + & & & & & + \\
\hline LRV 55/292 & + & & & & & + & + & + & & & & + \\
\hline LRV 295 & + & & & + & & & + & & & & & + \\
\hline LRV 697 & + & & & & & + & + & & & & & + \\
\hline
\end{tabular}

(LRV 55/67 and LRV 295). The remaining entries showed the slow band only. The inheritance of variations observed for MR, PGI, and TPI are discussed below.

Menadione reductase. Safflower entries showed two multibanded phenotypes (Fig. 1, MR, lanes 1 and 2; Fig. 2A). Eighteen entries showed the first phenotype while the remaining two entries, V51/211 and Frio 3176, displayed the second phenotype. Selfed progenies of the two MR phenotypes had the same banding pattern as their parents, indicating lack of allelic segregation. Crosses between these two homozygous types produced $F_{1}$ plants with seven bands (hybrid type). $\mathrm{F}_{2}$ progenies from three separate families displayed three phenotypes: parent 1 phenotype, hybrid phenotype, and parent 2 phenotype in the expected 1:2:1 ratio (Table 2 ). The observation of multiple zones of activity in inbred parents suggests that more than one homozygous locus controls the observed phenotypes; however, the possibility of modified forms of a single gene product cannot be ruled out. More work is needed to determine the genetic basis of MR in safflower.

Phosphoglucoisomerase. Two zones of activity stained for this enzyme (Fig. 1, PGI). The fast zone (PGI-1) was monomorphic with a single band in all safflower entries. In the slow zone (PGI2 ), three distinct banding patterns were scored. Inheritance analyses (Table 2) revealed that two alleles, F and S, at Pgi-2 locus control the observed variation. Like their parent, all selfed progenies of D51/192 showed the fast PGI-2 band. D51/192 was considered homozygous for the $\mathrm{F}$ allele controlling the fast band (genotype FF). On the other hand, all selfed progenies of ' $\mathrm{Ne}$ braska 10' displayed the slow PGI-2 band. 'Nebraska 10' was considered to be homozygous for the $\mathrm{S}$ allele controlling the slow band (genotype SS). $\mathrm{F}_{1}$ plants produced from crosses between the two parents had a 3-banded phenotype (genotype FS). The observation of the parental bands plus an intermediate band with a higher intensity in the hybrid plants (Fig. 2B) suggested that PGI acts as a dimeric enzyme in safflower. This is in agreement with the dimeric structure of this enzyme reported for other plant species (Hashemi et al., 1991). Backcrossing of the $\mathrm{F}_{1}$ plants (genotype FS) with 'D51/192' (genotype FF) produced two classes of progenies, 1-banded (genotype FF) and 3-banded (genotype FS), in the expected 1:1 ratio (Table 2 ). Isozyme analyses of the $\mathrm{F}_{2}$ progenies in four separate families revealed three phenotypes: fast, hybrid, and slow in the expected 1:2:1 ratio (Table 2, Fig. 2B).

'Nebraska 10', 'US-10', and '57-147' were homozygous for the $\mathrm{S}$ allele (Table 3). A2811, Frio 3176, and LRV 55/51 showed both $\mathrm{F}$ and $\mathrm{S}$ alleles in homozygous and heterozygous forms. The late rosette safflower LRV 55/292 was comprised of $9 \%$ hybrid and $91 \%$ homozygous fast phenotypes. The remaining 13 entries were homozygous for the F allele (Table 3).

Triosephosphate isomerase. TPI activity was detected in two zones (Fig. 1, TPI). The cathodal zone was monomorphic, and the anodal zone was polymorphic with three distinct banding patterns (Fig. 2C). This variation is controlled by two alleles, $\mathrm{F}$ and $\mathrm{S}$, at the Tpi-1 locus. This is demonstrated by the results from crosses between homozygous 'US-10' parent (genotype FF) and homozygous ' $57-147$ ' parent (genotype SS) and the subsequent isozyme analyses of $\mathrm{F}_{1}, \mathrm{BC}_{1}$, and $\mathrm{F}_{2}$ plants (Table 2). In safflower, like other plant species (Cousineau and Donnelly, 1992; Hoey and Parks, 1990; Kephart, 1990), TPI is active as a dimer. All of the eight late rosette types of safflower, the '57-147' Indian selection, and the Ute 3175 cultivar uniformly stained for the slow band and had the SS genotype (Table 3). The remaining 10 entries, all of spring type, were homozygous for the $\mathrm{F}$ allele.

This study revealed that isozyme variation is present for MR, 6PGDH, PGI, and TPI in safflower. The observation of a multibanded PGI-2 isozyme in some plants of otherwise homozygous entries is a reflection of limited, but detectable, outcrossing. Two of the spring-type safflower entries, V51/211 and Frio 3176, were distinct from the rest by having the type 2 MR phenotype (Table 3 ). In addition, V51/211 is characterized by having the FF genotype at the Pgi-2 locus. The spring- and winter-type safflowers were distinguishable with respect to their TPI-1 phenotype. All of the winter types had the SS genotype, while the majority of spring types were homozygous for the F allele. 
Isozyme genetic markers described in this study are effective tools for identification of hybrid individuals in this predominantly inbreeding species. However, the low amount of polymorphism will restrict the use of isozymes as a genetic tool.

\section{Literature Cited}

Adams, W.T. 1983. Applications of isozymes in tree breeding, p. 381400. In: S.D. Tanksley and T.J. Orton (eds.). Isozymes in plant genetics and breeding. Part A. Elsevier, Amsterdam.

Bassiri, A. 1977. Identification and polymorphism of cultivars and wild ecotypes of safflower based on isozyme patterns. Euphytica 26:701719.

Byrne, D.H. and T.G. Littleton. 1988. Electrophoretic characterization of diploid plums of the southeastern United States. J. Amer. Soc. Hort. Sci. 113:918-924.

Claassen, C.E. 1950. Natural and controlled crossing in safflower, Carthamus tinctorius L. Agron. J. 42:381-384.

Conkle, M.T., P.D. Hodgskiss, L.B. Nunnaly, and S.C. Hunter. 1982. Starch gel electrophoresis of conifer seeds: A laboratory manual. Gen. Tech. Rpt. PSW-64, Pacific Southwest For. and Range Expt. Sta., Berkeley, Calif.

Cousineau, J.C. and D.J. Donnelly. 1992. Genetic analysis of isozymes in raspberry. J. Amer. Soc. Hort. Sci. 117:996-999.

Estilai, A., A. Hashemi, and J.G. Waines. 1990. Isozyme markers for cultivar identification in guayule. HortScience 25:346-348.

Garvin, D.F. 1987. The inheritance and linkage of isozyme genes in tepary bean, Phaseolus acutifolius A. Gray. M.S. Thesis, Univ. of California, Riverside.

Gaur, P.M. and A.E. Slinkard. 1990. Genetic control and linkage relations of additional isozyme markers in chickpea. Theoretical and Applied Genet. 80:648-656.

Hashemi, A., A. Estilai, and B. Ehdaie. 1991. Inheritance of aconitase, shikimate dehydrogenase, and phosphoglucose isomerase in guayule. J. Amer. Soc. Hort. Sci. 116:737-739.
Heywood, J.S. 1980. Genetic correlations of edaphic differentiation and endemism in Gaillardia. PhD Diss., Univ. of Texas, Austin.

Hoey, M.T. and C.R. Parks. 1990. Isozyme inheritance in the genus Liquidambar L. J. Hered. 81:455-461.

Kephart, S.R. 1990. Starch gel electrophoresis of plant isozymes: A comparative analysis of techniques. Amer. J. Bot. 77:693-712.

Knowles, P.F. 1980. Safflower, p. 535-547. In: W.R. Fehr and H.H. Hadley (eds.). Hybridization of crop plants. Amer. Soc. Agron., Madison, Wis.

Knowles, P.F. 1982. Safflower, genetics and breeding, p. 89-101. In: Improvement of oilseed and industrial crops by induced mutations. Intl. Atomic Energy Agency, Vienna, Austria.

Knowles, P.F. 1989. Safflower, p. 363-374. In: G. Röbbelen, R.K. Downey, and A. Ashri (eds.). Oil crops of the world. McGraw-Hill, New York.

May, B. 1992. Starch gel electrophoresis of allozymes, p. 1-27. In: A.R. Hoelzer (eds.). Molecular genetic analysis of populations: A practical approach. Oxford Univ. Press, New York.

Moore, G.A. and G.B. Collins. 1983. New challenges confronting plant breeders, p. 25-58. In: S.D. Tanksley and T.J. Orton (eds.). Isozymes in plant genetics and breeding. Part A. Elsevier, Amsterdam.

O'Malley, D., N.C. Wheeler, and R.P. Guries. 1980. A manual for starch gel electrophoresis. Univ. of Wisconsin, Dept. of For. Staff Paper Ser. 11.

Rick, C.M. 1983. Tomato (Lycopersicon), p. 147-165. In: S.D. Tanksley and T.J. Orton (eds.). Isozymes in plant genetics and breeding. Part B. Elsevier, Amsterdam.

Soltis, D.E., C.H. Haufler, D.C. Darrow, and G.J. Gastony. 1983. Starch gel electrophoresis of fern: A compilation of grinding buffers, gel and electrode buffers, and staining schedules. Amer. Fern J. 73:9-27.

Thomas, C.A. 1964. Registration of 'US-10' safflower. Crop Sci. 4:446447.

Vles, R.O. and J.J. Gottenbos. 1989. Nutritional characteristics and food uses of vegetable oils, p. 63-86. In: G. Röbbelen, R.K. Downey, and A. Ashri (eds.). Oil crops of the world. McGraw-Hill, New York. 